\title{
The prevalence of synchronous self- citation practices at the institutional level
}

\author{
Sumeer Gul, Tariq Ahmad Shah and Huma Shafiq \\ Department of Library and Information Science, \\ University of Kashmir, INDIA \\ e-mail: sumeersuheel@gmail.com; \\ tariqahmadshah@gmail.com (corresponding author); \\ huma.msgr14@gmail.com
}

\begin{abstract}
Self-citation behaviour of authors affiliated to an institution was studied through synchronous selfcitation analysis. From 2004 through 2015, Web of Science and SciVerse Scopus databases indexed a total of 1503 articles by authors affiliated to a university in India. Self-citations were prevalent in 62.23 percent of works and significant difference is observed in self-citation pattern with regard to co-authorship, size of reference list, authors' productivity, citation age, citation over time, and reputation of source publications. Statistically positive correlation is observed between number of co-authors and number of self-citations ( $p<.01)$. Inter-institutional collaborative works attract more self-citations than works of intra-institutional efforts $(p<.01)$. Significant positive correlation exists between authors' productivity and share of self-citations $(p<.01)$. Regarding the currency of selfcitations, authors tend to cite more of their recent works than the works of others. Articles published in Journal Citation Reports (JCR) indexed sources have more number of self-citations than articles published in JCR excluded sources $(p<.01)$.
\end{abstract}

Keywords: Self-references; Self-citations; Synchronous self-citations; Author self-citations; University of Kashmir, India.

\section{INTRODUCTION}

Self-citations have remained the topic of interest for informatics from the days authors began to evaluate the performance and professional reputation of other researchers; and visibility and impact of journals they want to publish in. Studies based on self-citations begin with defining its meaning prior to discussing their findings. Self-citations have been looked at from different perspectives, such as author self-citation, journal self-citation, institutional self-citations (Van Raan 2008; Hendrix 2009), language self-citations, discipline self-citations and even webpage self-citations (Rousseau 1999). Depending on the relation between citing and cited article and the nature of the study being conducted, authors have defined self-citations accordingly. When an article(s) cites other article published in a journal in which the citing article appears, it is called journal self-citation; if the citing and cited paper have at least one author in common, it is called author self-citation. Institutional self-citation is said to occur, when citing and cited paper have at least one author affiliated to the same institution. Likewise, in discipline self-citation at least one of the authors of citing and cited papers are from the same discipline. However, self-citation is commonly applied to study journal and author self-citations which contribute greatly to the literature. 
There are two approaches to conduct author self-citation studies: either to look at references list (bibliography) which authors give at the end of their papers or to consult any citation database to know who have cited their publications. Lawani (1982) has respectively described them as "Synchronous" and "Diachronous" self-citation studies. Both approaches have their own benefits and limitations. In case of synchronous selfcitations, self-citations remain constant with time. Here authors can manipulate citations only at the time of preparation of manuscript. Once it is accepted and published in a journal, the number of self and other citations remains constant and cannot be modified further. However, diachronous self-citations studies are time dependent as citations are subject to change with time. Authors can manipulate the citation count as and when they need to, provided they remain active and get regularly published in indexed journals. Besides, diachronous self-citations are subject to the coverage of the citation databases. Such databases will count only those citations which come from journals indexed by them. For example, for the same article we can get different citation counts from the Web of Science, SciVerse Scopus, and Google Scholar because of the different coverage of indexed sources by these databases. Thus, synchronous approach is viable for studies which are concerned with intrinsic citation behaviour of authors i.e., those which are primarily concerned with author self-citations while other parameters are least involved. For studies which involve other parameters such as authors' visibility, influence and impact of their scholarly endeavour, diachronous approach seems to be more feasible.

Self-citation studies conducted so far have either highlighted this practice at the journal level or have analyzed authors who have published on a particular subject or theme. Very few studies could be traced out where this practice is observed at the national level (Aksnes 2003; Flower and Aksnes 2007) or institutional level (Van Raan 2008; Hendrix 2009). These studies have mostly adopted diachronous self-citations approach with the aid of citation databases, particularly the Web of Science, as data source. The current study though not the first of its kind but is amongst the first few that aims to observe selfcitation behaviour of authors affiliated to a particular institution via synchronous approach.

\section{OBJECTIVES}

The study is designed to examine the synchronous self-citation practices of authors at the institutional level (or meso level) irrespective of their subject affiliations. The objectives of this study are:

a. to examine the influence of co-authorship and collaboration on the count of selfcitations;

b. to examine self-citations in relation to total reference count of publications;

c. to determine the influence of authors' productivity on the practice of self-citations;

d. to determine the currency of self and other citations; and

e. to observe the influence of reputation of source publication on authors self-citation behaviour.

\section{LITERATURE REVIEW}

The literature on self-citation is huge and diverse. Ranging from mediocre to huge datasets, and from broader discipline to specific area of research, authors have accordingly 
observed this practice. Regardless of synchronous and diachronous approaches, authors report substantive difference in self-citation behaviour across disciplines and fields of study. Tagliacozzo (1977) observed 17.5 percent share of self-citations in the field of Plant Physiology and Neurobiology when book and monograph references are excluded from the total reference count. Dimitroff and Arlitsch (1995) found even distribution of articles with and without self-citations in the field of Library and Information Science. Synder and Bonzi (1998) found an average self-citation rate of 9.0 percent, varying from 16.0 percent in the Physical Sciences (Chemistry \& Geology); 6.0 percent in the Social Sciences (Economics \& Sociology) to 3.0 percent in the Humanities (Asian Studies \& Art History). In 2000, articles published on Diabetes Mellitus comprise nearly one-fifth of all citations as author selfcitations (Gami et al. 2004). In six biomedical journals, Falagas and Kavvidia (2006) noticed 19.0 percent self-citations in original research articles. Davarpanah and Amel (2009) observed variation in self-citation across four fields of Sciences classified under the Web of Science categories where General and Internal Medicine attracts the lowest i.e. 16.04 percent self-citations, Electronic Engineering with 28.77 percent, Plant Sciences obtains 30.25 percent, and Organic Chemistry has the highest share of 68.26 percent self-citations. In high-profile General Medicine journal articles, Kulkarni et al. (2011) witnessed approximately one in 15 citations as self-citations. Larcombe and Voss (2011) observed 17.75 percent of self-citations in original research articles published in 10 Physiology journals of American Physiological Society. Within five years of citation period, Shah, Gul and Gaur (2015) observed 39.0 percent Library and Information Science articles with selfcitations. In otolaryngology literature, Tolisano, Song and Cable (2015) found two-thirds of articles with self-citations.

While comparing self-citations with co-authorship, a number of studies reported an increase in the number of self-citations when more authors are associated with an article. Snyder and Bonzi (1998) reported it in the fields of Asian studies, Chemistry and Geology. Aksnes (2003) witnessed it in the publications by Norwegian authors. In the Ecological journal - Oecologia, Leimu and Koricheva (2005) also observed the same trend. Davarpanah and Amel (2009) witnessed significant positive correlation between the number of authors and self-citations in four Science disciplines (Electronic Engineering, General \& Internal Medicine, Organic Chemistry and Plant Sciences). Costas, Leeuwen and Bordon (2010) confirmed this phenomenon amongst publications by the Spanish National Research Council's scientists affiliated to the fields of Biology and Biomedicine and Material Science. In Ecology articles, Pichappan and Sarasvady (2002) observed that the proportion of both synchronous and diachronous self-citations increases with the increase in the number of authors. Tolisano, Song and Cable (2015) observed that the last researcher in the author list of collaborative works are more frequent self-citers and are more likely than lead authors to cite themselves. There are also a few studies which could not either find any relation, or observe negative correlation, between these two variables (Glanzel and Thijs 2004; Huston 2006; Shah, Gul and Gaur 2015; Snyder and Bonzi 1998; Tagliacozzo 1977). In Plant Physiology and Neurobiology, Tagliacozzo (1977) argued that the extent of self-citation did not appear to be related to the number of co-authors, and interpreted that when there is disparity in seniority among co-authors, the senior author provides most of the references, like a single author would provide in his/her publication. When the articles are co-authored by scientists of the same level of seniority, perhaps the authors exert a reciprocal restraining influence, so that each of them ends up citing less of his own work than he would if he were the only author. Huston (2006) also could not find any correlation in Archaeology papers between the number of authors and the quantity of self-citations. Snyder and Bonzi (1998) observed slight negative correlations in papers on Economics, Sociology and Art History. For macro level studies, Glanzel and Thijs (2004) 
reported that multi-authorship does not exaggerate the extent of self-citations. In the field of Library and Information Science, although Dimitroff and Arlistsch (1995) observed a positive relation between the number of self-citations and number of co-authors, Shah, Gul and Gaur (2015) could not ascertain such relationship. However, irrespective of the number of co-authors, Shah, Gul and Gaur (2015) found that collaborative works attract more citations than works produced at individual level.

Ageing of self-citations has also remained the interest of many authors. Studies found that authors tend to cite more of their recently published articles than the work of others (Aksnes 2003; Davarpanah and Amel 2009; Glanzel, Thijs and Schlemmer 2004; Peters and Van Raan 1991; Snyder and Bonzi 1998; Shah, Gul and Gaur 2015; Tagliacozzo 1977). Aksnes (2003) observed that the percentage of self-citations decreases when citations are traced for longer periods. Davarpanah and Amel (2009) revealed that the share of selfcitation decreases with growing time window. In general medicine literature, Kulkarni, Aziz, Shams and Busse (2011) observed a progressive decrease in self-citations after two years of publications, although they account for a greater percentage of citations early after publication. Snyder and Bonzi (1998) explained that for self-citations, authors are confined to their own articles published in their career, while for other works they are not subject to such restriction and can cite literature published much before they began their research careers. Tagliacozzo (1977) further added that the recency of self-citations is also related to the high degree of continuity (at least in the Biological Sciences) in the work of individual scientists.

Various studies have also been carried out to observe the relationship between selfcitations and sizes of reference list (Davarpanah and Amel 2009; as cited in Medoff 2006; Tagliacozzo 1977). To determine whether size of the bibliography (reference list) has to do with self-citations, Tagliacozzo (1977) adopted synchronous approach and concluded that the extent of self-citation is unaffected by the size of bibliography. Johnson (1997) found that the number of references in an article has no impact on the subsequent number of citations received, suggesting that many bibliographic entries are made merely to recognize potential editors and referees (as cited in Medoff 2006).

\section{MATERIALS AND METHOD}

To conduct the study at an institutional level, it is imperative to study the citation behaviour of researchers affiliated to a particular institution. The study is confined to the publications of authors affiliated to the University of Kashmir. University of Kashmir is the oldest university in the state of Jammu and Kashmir, India. With 43 departments and 13 unique research centres, it offers higher education and engages in research activities in different disciplines of Sciences, Social Sciences, Arts and Humanities. The institution was a logical choice for the authors of this study as they are affiliated to this institution.

Web of Science and SciVerse Scopus, the abstract and citation databases, were used as data sources for the study. The main reason for the use of these two databases instead of one is to get a comprehensive list of publications. The year 2004 was chosen as the starting year for the study because from this year onwards the University of Kashmir has begun to offer electronic access to scholarly journals and online databases on a large scale. Prior to it, access was confined to a limited number of resources that were mostly subscribed to in print form. With plethora of resources available, authors have an unlimited choice for referring to scholarly peer-reviewed literature. 
For both databases, relevant searching facilities were utilized and the search was confined to publications from 2004 through 2015 and to the following publication types: research articles, review articles and conference papers. Corrections, meeting abstracts and book reviews were excluded.

At SciVerse Scopus, search was conducted through 'affiliation search' facility. This feature enables one to determine and enlist works that are published by authors affiliated with a particular institution. The search was performed through the proper name of the institution - 'University of Kashmir'. At Web of Science, the search was performed through 'Address field' which performs the same function as that of 'affiliation search' facility of SciVerse Scopus. Unlike SciVerse Scopus, Web of Science assigns a unique name identifier to every institution and it is only through these identifiers one can get a complete list of publications authored by researchers affiliated to a particular institution. For University of Kashmir, Web of Science has assigned institutional identifier as - "univ kashmir". As such University of Kashmir's publications were identified through the search phrase "univ kashmir".

Results from both databases were clubbed together and after a thorough examination and elimination of duplicate records, a total of 1503 publications were identified. A total of 885 publications were indexed by both databases, 549 papers were found in SciVerse Scopus only while 69 were unique to Web of Science.

For each publication, essential bibliographic details (author, title, source, year of publication) along with references available at the end of each article were downloaded and recorded in a Microsoft-Excel file. The 2015 edition of Journal Citation Reports ${ }^{(R)}$ was consulted to get the Impact Factor of source publications in which authors have published their work.

Author-self-citation was considered when one of the citing author of an article and cited author in the reference list was similar. Self-citations were determined by direct examination of the reference list and all the publication types (e.g. journal articles, books, conference proceedings and reports) were taken into account. Problems with homonyms and author disambiguation such as spelling variance or misspelling of author names as reported by other studies were dealt with great care. In case of any doubt, authors were direct contacted (either personally or via email) and clarifications were sought.

Data were tabulated in Statistical Product and Service Solutions (SPSS) software. Initially descriptive statistics were used to examine the robustness of various statistical tests on the data. Highly skewedness and deviation from normal distribution rejected the application of parametric tests on the data. Thus, the current study is based on the results of nonparametric tests, using Spearman's correlation and Mann-Whitney $U$ statistics.

\section{RESULTS}

From 2004 through 2015, a total of 1503 articles by authors affiliated to the University of Kashmir are covered either in Web of Science or SciVerse Scopus. These articles enlist a total of 54664 references including 3835 self-citations. From this figure, 62.20 percent of articles bear a minimum of one self-citation each. 


\section{Authorship and Distribution of Self-Citations}

A total of 2299 authors have made contribution in the 1503 publications, of which 856 researchers from the University of Kashmir have collaborated with 1443 authors from other institutions. As evident from Table 1, 93.68 percent publications are a result of joint authorship while 6.32 percent publications have single authorship. The majority of publications are produced by a team of two authors (23.29 percent). There are only 3.26 percent publications which are an endeavour of a group of more than 10 authors each.

Table 1: Authorship Pattern for Articles Affiliated to the University of Kashmir (2004-2015)

\begin{tabular}{c||c||c||c||c||c}
\hline \hline $\begin{array}{c}\text { No. of } \\
\text { Authors }\end{array}$ & $\begin{array}{c}\text { No. of } \\
\text { Publications }\end{array}$ & Percentage & $\begin{array}{c}\text { No. of } \\
\text { Authors }\end{array}$ & $\begin{array}{c}\text { No. of } \\
\text { Publications }\end{array}$ & Percentage \\
\hline \hline 1 & 95 & 6.32 & 7 & 51 & 3.39 \\
\hline \hline 2 & 350 & 23.29 & 8 & 45 & 2.99 \\
\hline \hline 3 & 349 & 23.22 & 9 & 27 & 1.80 \\
\hline \hline 4 & 229 & 15.24 & 10 & 15 & 1.00 \\
\hline \hline 6 & 181 & 12.04 & & 49 & 3.26 \\
\hline \hline
\end{tabular}

Studies have shown that with the increase in the number of authors, share of self-citations also increases (Davarpanah and Amel 2009; Falagas and Kavvadia 2006; Glänzel 2002; Pichappan and Sarasvady 2002; Van Raan 1998). As per Costas, Leeuwen and Bordon (2010) each author comes with his share of expertise and past research experiences, and this more or less translates to additional self-citations. To check whether it holds true when authors affiliated to a particular institution are studied, Spearman's correlation test was conducted. Statistically significant, though weak, correlation is observed between the number of co-authors and number of self-citations ( $r=.143, p<.01,662, n=1503$ ).

\section{Collaboration and Self-Citations}

When it comes to collaborative works, out of 1408 co-authored publications, 825 articles (54.89 percent) are result of inter-institutional collaboration, i.e., in these publications authors from different institutions have worked together. The remaining 583 co-authored articles (38.79 percent) are endeavour of intra-institutional collaboration, i.e., authors from same institution have worked together (Table 2).

Table 2: Contribution in Different Authorship Collaboration

\begin{tabular}{l||c||c}
\hline \hline Collaboration & Frequency & Percentage \\
\hline \hline No Collaboration (individual works) & 95 & 6.32 \\
\hline \hline Intra-Institutional Collaboration & 583 & 38.79 \\
\hline \hline Inter-institutional Collaboration & 825 & 54.89 \\
\hline \hline
\end{tabular}

As per Herbertz (1995), collaborative papers from researchers of different institutions have higher citation rates than those from researchers of the same institution; nonetheless, the former usually sees higher self-citation rates. This study also tried to find out whether total reference count and number of self-citations in inter-institutional collaborative works differ from works produced from intra-institutional collaboration. As evident from Table 3, inter-institutional and intra-institutional collaborative works have statistically significant 
difference both in total reference count $(p<.01 ; n=1408)$ and in self-citations count $(p<.01$; $n=1408$ ). Mann-Whitney $U$ test confirms that the number of references are greater in inter-institutional collaborative works (median=31) than in intra-institutional collaborative works (median=26). Further inter-institutional works also have more number of selfcitations (median=2) compared to intra-institutional works (median=1).

Table 3: Mann-Whitney U Test between Total Reference Count and Self-citations in Interinstitutional and Intra-institutional Collaborative Works

\begin{tabular}{l|l||c|c|c|c||c}
\hline \hline & Collaboration & N & Median & $\begin{array}{c}\text { Mean } \\
\text { Rank }\end{array}$ & $\boldsymbol{U}$ & $\begin{array}{c}\text { Sig. (2- } \\
\text { tailed) }\end{array}$ \\
\hline \hline \multirow{2}{*}{$\begin{array}{l}\text { Total number } \\
\text { of References }\end{array}$} & Inter-Institutional & 825 & 31 & 737.19 & \multirow{2}{*}{213519} & .000 \\
\cline { 2 - 5 } & Intra-Institutional & 583 & 26 & 658.24 & & \\
\hline \multirow{2}{*}{$\begin{array}{l}\text { No. of Self- } \\
\text { citations }\end{array}$} & Inter-Institutional & 825 & 2 & 758.25 & \multirow{2}{*}{196142} & .000 \\
\cline { 2 - 5 } & Intra-Institutional & 583 & 1 & 628.44 & & \\
\hline \hline
\end{tabular}

\section{Total Reference Count and Self-Citations}

As evident from Table 4, the majority of articles (35.53 percent) listed references in the range of 21 and 40, followed by articles with references between one and 20 (32.53 percent). There are only 12.77 percent articles with more than 60 references. It is feasible to assume that authors who put a long list of references in their publications have also greater tendency to cite more of their own work while those who limit their reference count also do it with their own self-citations. Correlation test was conducted to confirm relationship between total reference count and number of self-citations. Statistically significant, though relatively moderate, positive correlation is observed between the two variables ( $r=.279 ; p<.01 ; n=1503)$.

Table 4: Number of references and Self-citations in Publications

\begin{tabular}{c|c|c}
\hline \hline Reference Range & No. of Publications & Percentage \\
\hline \hline $01-20$ & 489 & 32.53 \\
\hline $21-40$ & 534 & 35.53 \\
\hline \hline $41-60$ & 288 & 19.16 \\
\hline \hline$>60$ & 192 & 12.77 \\
\hline \hline
\end{tabular}

To examine this finding further, articles were divided in two groups: the first group includes articles with 40 or less references each and the other group having articles with more than 40 references. Results of Mann-Whitney $U$ Test, as reported in Table 5, indicate that the number of self-citations is statistically greater for articles having large list of references (median=3) than for articles having lesser number of references (median=1). However, no relation could be ascertained regarding the percentage of self-citations ( $p>.05)$. In other words, as the total number of references increase, so do the number of self-citations; however, the growth in the number of self-citations is not reflected proportionality with the growth of total reference count. Such kind of pattern is also observed by Huston (2006) in Archaeological articles and by Davarpanah and Amel (2009) 
in select fields of Science. The plausible explanation behind such results could be credited to limited choice amongst authors when it comes to cite their own previous works compared to other works which are always available in abundance.

Table 5: Mann-Whitney U Test of the Number and Proportion of Self-citations in Articles with Small and Large Set of Reference

\begin{tabular}{|c|c|c|c|c|c|c|}
\hline & $\begin{array}{l}\text { Total No. of } \\
\text { References }\end{array}$ & $\begin{array}{l}\text { No. of } \\
\text { Articles }\end{array}$ & Median & $\begin{array}{l}\text { Mean } \\
\text { Rank }\end{array}$ & $\mathbf{U}$ & $\begin{array}{l}\text { Sig. (2- } \\
\text { tailed) }\end{array}$ \\
\hline \multirow{2}{*}{$\begin{array}{l}\text { No. of Self- } \\
\text { citations }\end{array}$} & $>40$ & 480 & 3 & 892.86 & \multirow{2}{*}{231986.5} & \multirow{2}{*}{.000} \\
\hline & $\leq 40$ & 1023 & 1 & 685.91 & & \\
\hline \multirow{2}{*}{$\begin{array}{l}\% \text { age of } \\
\text { Self-citations }\end{array}$} & $\leq 40$ & 1023 & 4.44 & 723.81 & \multirow{2}{*}{177905} & \multirow{2}{*}{.079} \\
\hline & $>40$ & 480 & 5.26 & 765.23 & & \\
\hline
\end{tabular}

\section{Authors' Productivity and Self-citations}

As evident from Table 6, nearly 49 percent authors (419) publish only one article each and 14.49 percent (124) published two articles each. There are only 88 authors (9.26 percent) who have more than 10 publications each. Davarpanah and Amel (2009) opined that authors who publish a lot have more opportunities to cite their own previous works rather than those who have limited number of publications. As such the number of self-citations will increase with the increase in the number of articles published by an author. To verify the same, Spearman's correlation test was conducted between authors' productivity and respective average share of self-citations in their publications. Spearman's correlation test affirms positive, statistically significant relationship of author's productivity with his/her average share of self-citations $(r=.267 ; p<.01 ; n=856)$. In other words, as the productivity of an author increases the average share of self-citations also increases.

Table 6: Individual Author's Productivity

\begin{tabular}{c|c||c||c||c|c}
\hline $\begin{array}{c}\text { No. of } \\
\begin{array}{c}\text { Publications } \\
\text { each }\end{array}\end{array}$ & $\begin{array}{c}\text { No. of } \\
\text { Authors (\%) }\end{array}$ & $\begin{array}{c}\text { No. of } \\
\text { Publications } \\
\text { each }\end{array}$ & $\begin{array}{c}\text { No. of } \\
\text { Authors (\%) }\end{array}$ & $\begin{array}{c}\text { No. of } \\
\text { Publications } \\
\text { each }\end{array}$ & $\begin{array}{c}\text { No. of } \\
\text { Authors (\%) }\end{array}$ \\
\hline \hline 1 & $419(48.95)$ & 14 & $6(0.7)$ & 28 & $2(0.23)$ \\
\hline \hline 2 & $124(14.49)$ & 15 & $4(0.47)$ & 30 & $3(0.35)$ \\
\hline \hline 3 & $68(7.94)$ & 16 & $3(0.35)$ & 31 & $2(0.23)$ \\
\hline \hline 4 & $48(5.61)$ & 17 & $4(0.47)$ & 32 & $1(0.12)$ \\
\hline \hline 5 & $34(3.97)$ & 18 & $1(0.12)$ & 33 & $1(0.12)$ \\
\hline \hline 7 & $22(2.57)$ & 19 & $2(0.23)$ & 36 & $1(0.12)$ \\
\hline \hline 9 & $18(2.1)$ & 20 & $4(0.47)$ & 38 & $1(0.12)$ \\
\hline \hline 10 & $19(2.22)$ & 21 & $3(0.35)$ & 40 & $1(0.12)$ \\
\hline \hline 11 & $16(1.87)$ & 22 & $6(0.7)$ & 43 & $1(0.12)$ \\
\hline \hline 12 & $9(1.05)$ & 23 & $1(0.12)$ & 50 & $2(0.23)$ \\
\hline \hline 13 & $9(1.05)$ & 25 & $1(0.12)$ & 52 & $1(0.12)$ \\
\hline \hline
\end{tabular}

Figures in parentheses indicate percentage 


\section{Publication and Reference behaviour of authors over time}

Over the years, one can observe a cumulative annual growth rate of 23.75 percent in the number of publications. Also a cumulative annual growth rate of 4.41 percent is also observed in the proportion of self-citation bearing articles. As evident from Table 7, the maximum number of 271 articles are published both in the year 2014 and 2015. A maximum of 74.17 percent of articles published in 2015 bear one self-citation each.

Table 7: Yearly Pattern of Publications, Average Reference Count and Average Self-citations

\begin{tabular}{c||c||c||c|c}
\hline \hline Year & $\begin{array}{c}\text { Total no. of } \\
\text { articles }\end{array}$ & $\begin{array}{c}\text { Articles with Self- } \\
\text { citations }\end{array}$ & $\begin{array}{c}\text { Average no. of } \\
\text { References* }\end{array}$ & $\begin{array}{c}\text { Average no. of Self- } \\
\text { citations* }\end{array}$ \\
\hline \hline 2004 & 26 & $12(46.15 \%)$ & $23.77 \pm 22.65$ & $2.42 \pm 4.46$ \\
\hline \hline 2005 & 29 & $16(55.17 \%)$ & $18.79 \pm 15.11$ & $1.66 \pm 2.19$ \\
\hline \hline 2006 & 46 & $35(76.09 \%)$ & $22.22 \pm 13.82$ & $2.11 \pm 2.65$ \\
\hline 2007 & 62 & $48(77.42 \%)$ & $27.92 \pm 23.85$ & $2.42 \pm 2.58$ \\
\hline \hline 2008 & 81 & $47(58.02 \%)$ & $22.23 \pm 17.51$ & $2.06 \pm 4.52$ \\
\hline \hline 2009 & 84 & $53(63.10 \%)$ & $25.62 \pm 20.13$ & $1.80 \pm 2.32$ \\
\hline \hline 2010 & 93 & $63(67.74 \%)$ & $35.82 \pm 31.06$ & $2.72 \pm 3.95$ \\
\hline \hline 2011 & 149 & $93(62.42 \%)$ & $35.99 \pm 28.94$ & $2.13 \pm 3.08$ \\
\hline \hline 2012 & 174 & $96(55.17 \%)$ & $34.61 \pm 29.13$ & $1.93 \pm 2.73$ \\
\hline \hline 2013 & 217 & $148(68.20 \%)$ & $39.99 \pm 31.37$ & $2.56 \pm 3.42$ \\
\hline \hline 2014 & 271 & $183(67.53 \%)$ & $39.58 \pm 29.92$ & $2.81 \pm 3.64$ \\
\hline \hline
\end{tabular}

* Mean \pm SD

It cannot be denied that the number of web resources especially those that are on open access have increased in the last two decades. Even toll-based publishers are now allowing their authors to deposit a copy of their articles in subject/institutional repositories (either immediately or after embargoed period). When it comes to subscribed resources, institutions also attempt to widen their access base of subscribed resources for their users. Besides, advancements in ICT have made it easier to search, retrieve and share relevant literature. Thus, it can be assumed that as we move forward in time, the size of reference list might have increased as the number of accessible resources to authors increase. We conducted Spearman's correlation test to gauge whether it holds true or not. Statistically significant correlation was observed between total reference count and year of publication $(r=.246 ; p<.01 ; n=1503)$. The current finding is in conformity with the results of Lin and Huang (2012) who also observed that with the passage of time authors tend to cite more. Regarding quantity of self-citations, there also exists relation between these two variables $(r=.108 ; p<.01 ; n=1503)$.

\section{Currency of Self and Other references}

Regarding the currency of references, only those references are analysed which include their year of publication. Of the total 54664 references enlisted in the 1503 studied publications, 53840 references ( 98.49 percent) mentioned their year of publication while the remaining 824 references ( 1.51 percent) are cited without publication date.

As depicted in Figure 1, the average range of self-citations is found to be 32 years with halflife of 2-3 years, while 75 percent self-citations are 5-6 years old, and 90 percent are 14-15 years old. In case of other-citations, the average range of citations is found to be 433 years (out of coverage in Figure 1). With half-life of 11-12 years, 75 percent citations are 20-21 
years old and 90 percent are 33-34 years old. Thus, it is clear that self-citations are much younger than other citations. Regardless of whether the study is conducted through synchronous or diachronous approach, authors have also observed that self-citations tend to be more for recent works than citations to other works (Lin and Huang 2012; Synder and Bonzi 1998; Tagliacozzo 1977). Amongst the most probable reasons, such behaviour may be attributed to limited research experience of authors. Authors could only have few decades of active research period and as such, the window for self-citation is least compared to other-citations where such limitation does not exist. Also, the interest of researchers may change over time and it is not necessary that they stick to the same problem throughout their professional careers. Researchers may explore many new areas within their field of specialization, which may or may not have any potential link with their previous works. As such if a researcher divulges into a new area, he/she is more likely to be treated as a young researcher rather than a prolific author.

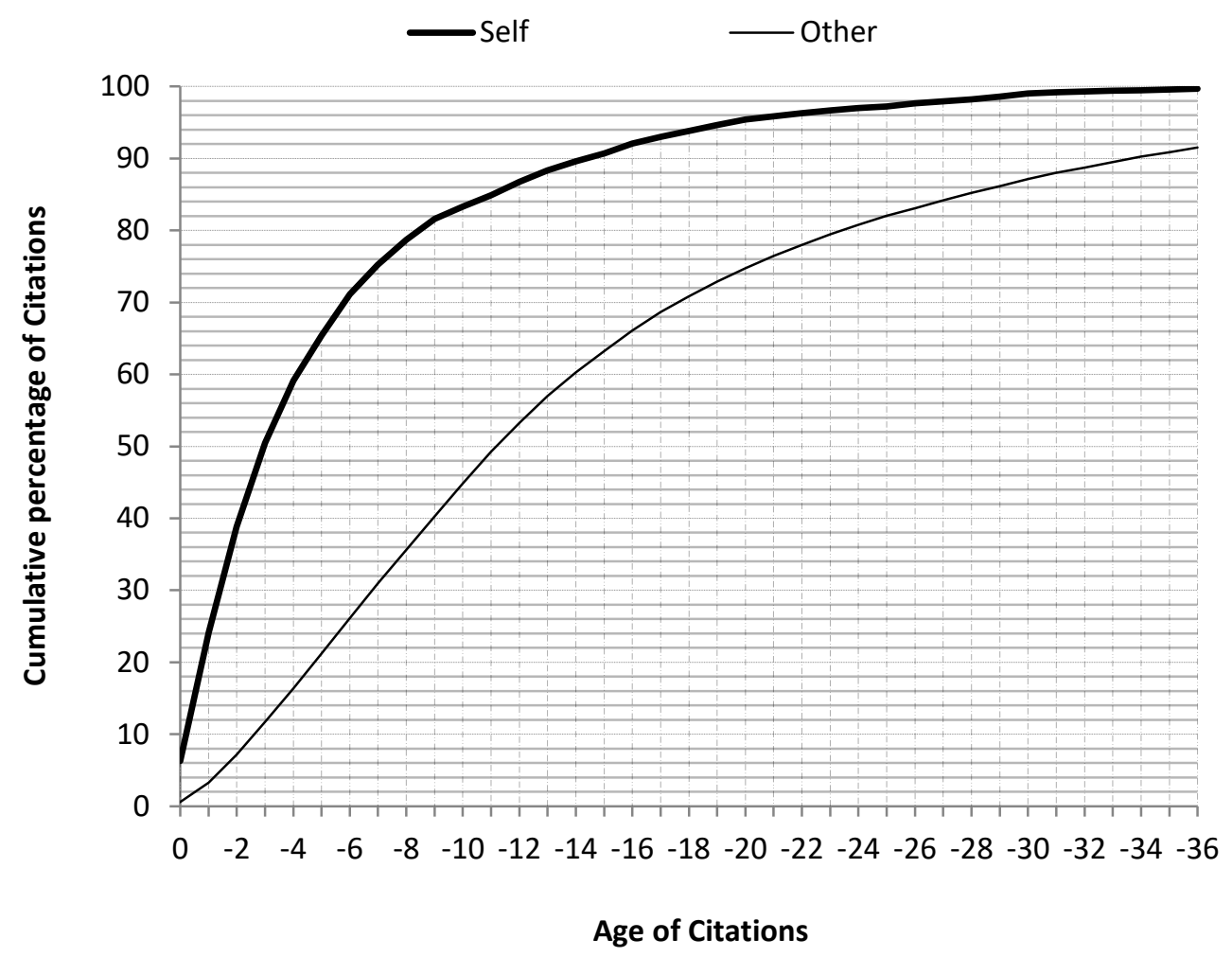

Figure 1: Age of Self and Other Citations

\section{Journal Reputation and Author Self-citations}

To check whether reputation of source publication is related to authors' self-citation, we consulted the 2015 edition of Journal Citation Reports (JCR) as a measure of reputation of source publications and correlated with the self-citation behaviour of authors. Out of 740 sources in which authors have published their works, 471 sources (i.e. journal titles) are included in JCR and have published a total of 913 articles. The remaining 269 sources which are excluded from JCR publish a total of 590 articles.

Spearman's Correlation test was performed on those articles whose source publications are included in Journal Citation Reports. A positive correlation was observed between 
reputation of source publication and size of reference list ( $r=.442 ; p<0.01 ; n=913)$ and also between reputation of source publication and number of self-citations $(r=.261 ; p<0.01$; $n=913$ ). Studies by Herbertz (1995) and Leblond (2012) also observed significant positive co-relationship between reputation of source publication and share of self-citations. Leblond (2012) summarized that high impact journals often choose articles written by large group of authors with high research productivity while novice authors most preferably select low impact journals to publish their work.

An attempt was also made to assess whether there exists any relation between total references count and number of self-citations in articles whose source publication were indexed in JCR and in articles whose source were not indexed in JCR. To check the same, data are converted into two groups: one group included JCR-indexed articles and the other group had JCR-excluded articles. Mann-Whitney $U$ Test confirms statistically significant difference in the number of total references $(p<.01)$ and the number of self-citations $(p<.01)$ in articles published in JCR-indexed and JCR-excluded sources. Total number of references are greater in articles published in JCR-indexed sources (median=35) than in articles published in JCR-excluded sources (median=21). The number of self-citations are also greater in articles published in JCR-indexed sources (median=2) than in articles published in JCR-excluded sources (median=1). Table 8 presents these findings.

Table 8: Mann-Whitney U Test of References and Self-citations in Articles Published in JCR (2015) Included and Excluded Sources

\begin{tabular}{|c|c|c|c|c|c|c|}
\hline & $\begin{array}{c}\text { Source } \\
\text { Publications }\end{array}$ & $\begin{array}{l}\text { No. of } \\
\text { Articles }\end{array}$ & Median & $\begin{array}{c}\text { Mean } \\
\text { Rank }\end{array}$ & $u$ & $\begin{array}{l}\text { Asymp. } \\
\text { Sig. (2- } \\
\text { tailed) }\end{array}$ \\
\hline \multirow{2}{*}{$\begin{array}{l}\text { Total no. of } \\
\text { References }\end{array}$} & JCR - included & 913 & 35 & 858.20 & \multirow{2}{*}{172372} & \multirow{2}{*}{.000} \\
\hline & JCR - excluded & 590 & 21 & 587.66 & & \\
\hline \multirow{2}{*}{$\begin{array}{l}\text { No. of Self- } \\
\text { Citations }\end{array}$} & JCR - included & 913 & 2 & 838.24 & \multirow{2}{*}{190601} & \multirow{2}{*}{.000} \\
\hline & JCR - excluded & 590 & 1 & 618.55 & & \\
\hline
\end{tabular}

\section{DISCUSSION AND CONCLUSION}

Self-citations may be regarded as a natural phenomenon which exists in the scholarly literature in a significant proportion (Fowler and Aksnes 2007). It may be noted that where excessive self-citations are regarded as an abuse (Lawani 1982; Martyn 1975), their prevalence in fair number is perceived as normal (Aksnes 2003) and even commendable, if only to avoid the repetition of already published information (Macdonald and Kam 2011). Authors have mostly studied self-citations in specific subject fields, such as Plant Physiology and Neurobiology (Tagliacozzo 1977); Library and Information Science (Dimitroff and Arlitsch 1995; Shah, Gul and Gaur 2015); Ecology (Pichappan and Sarasvady 2002); Diabetes Mellitus (Gami et al. 2004); General Medicine (Kulkarni et al. 2011); Otolaryngology (Tolisano, Song and Cable 2015), and have mostly examined self-citations with regard to their frequency in an article (the number of times they occur in an article). To the best of our knowledge this study is amongst the first few to assess the prevalence of authors' synchronous self-citation behaviour at an institutional level. 
Regarding the relationship between the number of co-authors and the number of selfcitations, statistically significant, though weak, correlation is observed. Increase in the number of actors in the scientific communication positively affects the self-citation behaviour. Adding authors to papers also means adding more self-citations, as every author will share his/her work in the form of citations as they have preference for their own works (Van Raan 1998).

When it comes to collaboration, works that are result of inter-institutional collaboration attract more self-citations than works of intra-institutional efforts. The possible reason as visualised by Persson, Glänzel and Danell (2004) is that authors from different institutions can be assumed to have different information exposures and habits.

Concerning the total reference count and quantity of self-citations, statistically significant correlation exists. Authors' productivity is found to be positively correlated with share of self-citations. The share of self-citations increases with the increase in the productivity of an author. This could be attributed more to the fact of incrementality of knowledge as current research builds upon and depends fully upon previous research (Snyder and Bonzi 1998).

Regarding the currency of self-citations, authors are found to cite more of their recent works than the works of other people. With the rapid expansion in the scientific world, new researchers enter in the field of research, which have a limited set of works to be cited which for sure will be recent in their origin. With the limited number of recent works, they tend to cite those works which result in "self-citation recency phenomenon". Change in the publication activity of the authors over a period of time can also be contributed or related with this phenomenon. However, the fact that newcomers, transients, and terminators, i.e., scientists who are entering and/or leaving the community of active authors will surely have an impact on self-citations which will result in citing those works which are recent in their origin (Persson, Glänzel and Danell 2004).

As far as relationship between reputation (Impact Factor) of source publication with the total number of references and number of self-citations is concerned, a positive correlation is observed. The point of interest is that the value of correlation coefficient between Impact Factor and number of self-citations is much higher than between Impact Factor and total reference count. Besides, it is also observed that articles published in JCR-indexed sources have larger size of references and count of self-citations than articles published in JCR-excluded sources.

In conclusion, although this study has observed association of varying degree between selfcitations with parameters like co-authorship, collaboration, authors' productivity, total reference count, and reputation of source publications, it would be early to extrapolate the findings. The authors have observed this phenomenon in one institution only. Further, efforts are needed to determine the robustness of findings in other institutions, where authors work in different social, cultural, and educational setups.

\section{ACKNOWLEDGEMENT}

This research received no specific grant from any funding agency in the public, commercial, or not-for profit sectors. 


\section{REFERENCES}

Aksnes, D.W. 2003. A macro study of self-citation. Scientometrics, Vol. 56, no.2: 235-246. DOI: 10.1023/A:1021919228368.

Costas, R., Leeuwen, T.N.V. and Bordons, M. 2010. Self-citations at the meso and individual levels: effects of different calculation methods. Scientometrics, Vol. 82, no.3: 517-537. DOI: 10.1007/s11192-010-0187-7.

Davarpanah, M. R. and Amel, F. 2009. Author self-citation pattern in science. Library Review, Vol. 58, no.4: 301-309. DOI: 10.1108/00242530910952846.

Dimitroff, A. and Arlitsch, K. 1995. Self-citations in the Library and Information Science Literature, Journal of Documentation. Vol. 51, no.1: 44 - 56. DOI: 10.1108/eb026942

Falagas, M. E. and Kavvadia, P. 2006. "Eigenlob": Self-citation in biomedical journals. The FASEB Journal, Vol. 20, no.8: 1039.

Flower, J.H. and Aksnes, D.W. 2007. Does self-citation pay? Scientometrics, Vol. 72, no.3: 427-437. DOI: 10.1007/s11192-007-1777-2.

Gami, A.S., Montori, V.M., Wilczynski, N.L. and Haynes, R.B. 2004. Author self-citation in the diabetes literature. Canadian Medical Association Journal, Vol. 173, no.13: 192527. DOI:10.1503/cmaj.1031879.

Glänzel, W. 2002. Co-authorship patterns and trends in the sciences (1980-1998). A bibliometric study with implications for database indexing and search strategies, Library Trends, Vol. 50, no.3: 461-473.

Glänzel, W. and Thijs, B. 2004. Does co-authorship inflate the share of self-citations?, Scientometrics, Vol. 61, no.3: 395-404. DOI: 10.1023/B:SCIE.0000045117.13348.b1.

Glanzel, W., Thijs, B. and Schlemmer, B. 2004. A bibliometric approach to the role of author self-citations in scientific communication. Scientometrics, Vol. 59, no.1: 63-77.

Haung, M. and Lin, W.C 2012. The influence of journal self-citations on journal impact factor and immediacy index. Online Information Review, Vol. 36, no.5: 639-654. DOI 10.1108/14684521211275957.

Hendrix, D. 2009. Institutional self-citations rates: a three year study of universities in the United States. Scientometrics, Vol. 81, no.2: 321-331. DOI: 10.1007/s11192-008-2160-2

Herbertz, H. 1995. Does it pay to cooperate? A bibliometric case study in molecular biology. Scientometrics, Vol. 33, no.1: 117-22. DOI: 10.1007/BF02020777.

Hutson, S.R. 2006. Self-citation in archaeology: Age, gender, prestige, and the self. Journal of Archaeological Method and Theory, Vol. 13, no.1: 1-18. DOI: 10.1007/s10816-0069001-5.

Kulkarni AV., Aziz, B., Shams I. and Busse JW. 2011. Author self-citation in the general medicine literature. PLOS ONE, Vol. 6, no. 1: e20885. DOI:10.1371/journal.pone.0020885.

Larcombe, A. N. and Voss, S.C. 2011. Self-citation in American Physiological Society Journals. Scientometrics, Vol. 87, no.2: 347-356. DOI 10.1007/s11192-010-0328-z.

Lawani, S. 1982. On the heterogeneity and classification of author self-citations, Journal of the American Society for Information Science. Vol. 33, no.5: 281-284. DOI: 10.1002/asi.4630330506.

Leblond, M. 2012. Author self-citations in the field of ecology, Scientometrics, Vol. 91 (3: 943-953. DOI: 10.1007/s11192-011-0565-9.

Leimu, R. and Koricheva, J. 2005. Does scientific collaboration increase the impact of ecological articles? Bioscience, Vol. 55, no.5: 438-443. DOI: 10.1641/00063568(2005)055[0438:DSCITI]2.0.CO;2. 
Lin, W.C. and Huang, M. 2012. The relationship between co-authorship, currency of references and author self-citations. Scientometrics, Vol. 90, no.2: 343-360. DOI: 10.1007/s11192-011-0523-6.

Macdonald, S. and Kam, J. 2011. The skewed few: People and papers of quality in management studies. Organization, Vol. 18, no.4: 467-475. DOI: 10.1177/1350508411403533.

Martyn, J. 1975. Citation analysis. Journal of Documentation, Vol. 31, no.4: 290-297. DOI: 10.1108/eb026610.

Medoff, M.H. 2006. The efficiency of self-citations in economics. Scientometrics, Vol. 69, no.1: 69-84. DOI: 10.1007/s11192-006-0139-4.

Persson, O., Glänzel, W. and Danell, R. 2004. Inflationary bibliometric values: The role of scientific collaboration and the need for relative indicators in evaluative studies. Scientometrics, Vol. 60, no.3: 421-432. DOI: 10.1023/B:SCIE.0000034384.35498.7d.

Peters, H.P.F. and Van Raan, A.F.J. 1991. Structuring scientific activities by co-author analysis. An exercise on a university faculty level, Scientometrics, Vol. 20, no.1: 235255. DOI: 10.1007/BF02018157.

Pichappan, P. and Sarasvady, S. 2002. The other side of the coin: the intricacies of author self-citations. Scientometrics, Vol. 54, no.2: 285-290. DOI: 10.1023/A:1016070029935

Rousseau, R. 1999. Temporal differences in self-citation rates of scientific journals. Scientometrics, Vol. 44, no.3: 521-531. DOI: 10.1007/BF02458493.

Shah, T.A, Gul, S. and Gaur, R. 2015. Authors self-citation behaviour in the field of Library and Information Science. Aslib Proceedings, Vol. 67 no. 4; 458-468. DOI: 10.1108/AJIM10-2014-0134.

Snyder, H. and Bonzi, S. 1998. Patterns of self-citation across disciplines (1980-1989). Journal of Information Science, Vol. 24, no. 6: 431-435. DOI: 10.1177/016555159802400606.

Tagliacozzo, R. 1977. Self-citations in scientific literature. Journal of Documentation, Vol. 33, no. 4: 251 - 265. DOI: 10.1108/eb026644.

Tolisano, A.M., Song, S.A. and Cable, B.B. 2015. Author self-citation in the otolaryngology literature: A pilot study. Head and Neck Surgery, Vol. 154, No. 2: 282-286. DOI: 10.1177/0194599815616111.

Van Raan, A.F.J. 1998. The influence of international collaboration on the impact of research results: some simple mathematical considerations concerning the role of selfcitations. Scientometrics, Vol. 42, no.3: 423-428. DOI: 10.1007/BF02458380.

Van Raan, A.F.J. 2008. Bibliometric statistical properties of the 100 largest European research universities: Prevalent scaling rules in the science system. Journal of the American Society for Information Science and Technology, Vol. 59, no. 3: 461-475. DOI: 10.1002/asi.20761. 